\title{
Combinatorial control of Drosophila eye development by Eyeless, Homothorax, and Teashirt
}

\author{
Jose Bessa, ${ }^{1}$ Brian Gebelein, ${ }^{2}$ Franck Pichaud, ${ }^{3}$ Fernando Casares, ${ }^{1,4}$ and Richard S. Mann ${ }^{2,4}$ \\ ${ }^{1}$ Instituto de Biologia Molecular e Celular (IBMC), 4150-180 Porto, Portugal; ${ }^{2}$ Department of Biochemistry and Molecular \\ Biophysics, Columbia University, New York, New York 10032, USA; ${ }^{3}$ Department of Biology, New York University, \\ New York, New York 10003, USA
}

In Drosophila, the development of the compound eye depends on the movement of a morphogenetic furrow (MF) from the posterior (P) to the anterior (A) of the eye imaginal disc. We define several subdomains along the A-P axis of the eye disc that express distinct combinations of transcription factors. One subdomain, anterior to the MF, expresses two homeobox genes, eyeless (ey) and homothorax (hth), and the zinc-finger gene teashirt (tsh). We provide evidence that this combination of transcription factors may function as a complex and that it plays at least two roles in eye development: it blocks the expression of later-acting transcription factors in the eye development cascade, and it promotes cell proliferation. A key step in the transition from an immature proliferative state to a committed state in eye development is the repression of hth by the BMP-4 homolog Decapentaplegic (Dpp).

[Keywords: eyeless; homothorax; teashirt; proliferation; differentiation; eye development]

Received May 20, 2002; revised version accepted July 19, 2002.

During animal development, cell proliferation must be tightly coordinated with differentiation. For each body part to develop properly, there must be sufficient proliferation to provide enough cells to form the final structure. There must also be mechanisms to ensure that proliferation is terminated and that differentiation of specific cell types begins at the correct times. Finally, there must be mechanisms to ensure that each body part will be proportioned correctly, both in relation to itself and to the rest of the organism. Although critical to animal development, how these processes are controlled and coordinated with each other remains largely unknown and is therefore a focus in biology at present.

The development of the compound eye of Drosophila melanogaster provides a unique experimental system in which differentiation and proliferation during development can be readily examined. The adult fly eye is comprised of $\sim 800$ units, called ommatidia, which are packed in a regular hexagonal array (Ready et al. 1976). Each ommatidium contains a collection of 8 photoreceptor cells and 11 accessory cells. These cell types form in a stereotyped and lineage-independent manner in the wake of a morphogenetic furrow (MF) that sweeps across the eye imaginal disc during the third larval instar stage of Drosophila development. The MF initiates at the pos-

${ }^{4}$ Corresponding authors.

E-MAIL fcasares@ibmc.up.pt; FAX 35-122-609-9157.

E-MAIL rsm10@columbia.edu; FAX (212) 305-7924.

Article and publication are at http://www.genesdev.org/cgi/doi/10.1101/ gad.1009002. terior $(\mathrm{P})$ margin of the eye disc and moves across the disc in the anterior (A) direction. Ahead (anterior) of the $\mathrm{MF}$, cells are not committed to any particular cell type and divide in an unsynchronized manner (Wolff and Ready 1991). As the MF moves across the disc, it coordinates the cell cycle and initiates photoreceptor differentiation, in part by inducing the expression of the proneural gene atonal (ato; Jarman et al. 1994; Baker et al. 1996; Dominguez 1999; for review, see Baker 2001). After an initial low level and uniform expression in the MF, ato is up-regulated in single, isolated cells that will develop into the first committed cell in each ommatidium, the R8 photoreceptor. Behind (posterior) the MF, ommatidia form in a stepwise manner as additional cells are recruited to join the $\mathrm{R} 8$ cell. Through a reiterative use of the epidermal growth factor (EGF) receptor pathway, these cells differentiate into the seven remaining photoreceptor cells and accessory cells (Freeman 1996). Thus, at any one time during the third-instar stage, cells at multiple stages of differentiation and commitment are displayed along the A-P axis of the eye disc (for review, see Treisman and Heberlein 1998; Reifegerste and Moses 1999).

The progression of the MF across the eye disc and differentiation of ommatidial cell types uses at least three cell-cell signaling pathways. Hedgehog $(\mathrm{Hh})$, secreted by differentiating photoreceptors in and behind the MF, signals to more anterior cells to initiate photoreceptor differentiation (for review, see Treisman and Heberlein 1998). To accomplish this, Hh induces at least two sec- 
ondary signals, Dpp, a secreted molecule, and Delta (D1), a transmembrane ligand in the Notch pathway. Dpp acts at long range ahead of the MF to induce a pre-proneural (PPN) state (Greenwood and Struhl 1999; Baonza and Freeman 2001). One marker for the PPN domain is hairy, which encodes a transcriptional repressor of ato. Once Dpp has induced the PPN state Dl, also expressed in cells in and behind the MF, represses hairy and extramacrochaete, another inhibitor of ato (Brown et al. 1995; Baonza and Freeman 2001). The down-regulation of these repressors close to the MF triggers the subsequent up-regulation of ato in single R8 cells.

Although many transcription factors are known to be important for eye development, how these factors collaborate with the Hh, Dpp, and N signaling pathways is less clear. Two Drosophila Pax-6 homologs, ey and twin of eyeless (toy), play a major role in the transcription factor network that controls eye development (for review, see Desplan 1997; Treisman 1999). Both ey and toy have the ability to induce eye morphogenesis when expressed ectopically during fly development (Halder et al. 1995; Czerny et al. 1999). Three other transcription factors have also been shown to be required for eye development and appear to function downstream of ey and toy, at least during the early phases of eye development, sine oculis (so), eyes absent (eya), and dachshund (dac; Bonini et al. 1993; Cheyette et al. 1994; Mardon et al. 1994). Of these three, only so encodes a protein with an obvious DNA-binding domain. However, Eya binds to both Dac and So, suggesting that these three proteins may function as a complex (Chen et al. 1997; for review, see Des plan 1997; Pignoni et al. 1997; Treisman 1999). so appears to be a direct target of Ey, consistent with the idea that so is genetically downstream of Ey (Niimi et al. 1999).

We show here that the uncommitted cells anterior to the MF express different combinations of transcription factors, suggesting that these cells are not equivalent to each other. The transcription factors expressed by these cells are Ey, Hth, a TALE-class homeodomain protein (Rieckhof et al. 1997; Pai et al. 1998), and Tsh, a zincfinger transcription factor (Fasano et al. 1991). We show how the different expression domains for these factors are generated by signals coming from the MF. Further, we present experiments suggesting that Ey, Hth, and Tsh may function together as a complex. Our experiments suggest that this complex plays at least two roles in eye development: to promote cell proliferation in eye discs and to prevent the premature expression of the more downstream transcription factors, so, eya, and dac. Thus, in Drosophila eye development, the regulation of Hth, Ey, and Tsh is critical for the transition from an uncommitted proliferative state to a mature differentiated state.

\section{Results}

hth, ey, and tsh patterns define three domains in the anterior of the eye disc

Anterior to the MF, at least three cell types can be distinguished by the patterns of Hth, Ey, and Tsh expres- sion (Fig. 1). The most anterior domain in the eye field, which is next to the antennal portion of the eye-antennal imaginal disc, expresses Hth, but not Tsh or Ey (region I). In a slightly more posterior domain, all three of these factors are coexpressed (region II). In a more posterior domain, Tsh and Ey, but not Hth, are coexpressed. This domain, which also expresses hairy (Greenwood and Struhl 1999; Baonza and Freeman 2001), is equivalent to the pre-proneural (PPN) domain (see below; Fig. 1). The MF, marked by the expression of Dpp, is immediately posterior to the PPN domain, and therefore abuts Tsh + Ey-expressing cells (Fig. 1G).

Domain II is the only region of the eye-antennal imaginal disc that strongly expresses all three of these transcription factors. Posterior to the MF, Hth, but not Tsh or Ey, is expressed in cells committed to become pigment cells. Hth and Ey, but not Tsh, are coexpressed in a narrow row of margin cells that frame the eye field and separate the main epithelium of the eye disc from the peripodial membrane (Figs. 1A,B and 7C, below; Bryant 1978). Finally, Hth is also strongly expressed in peripodial cells, whereas Ey and Tsh are weakly expressed in a subset of these cells (Fig. 1F; data not shown).

We also examined the expression patterns of So, Dac, and Eya in wild-type eye discs. All three of these transcription factors are expressed in the PPN domain but not in domain II. Their expression domains have the same anterior limit but different posterior limits (Fig. 1; data not shown). Furthermore, the anterior limits of their expression domains are not sharp, but instead decrease gradually as $\mathrm{Hth}$ levels increase (Fig. 1F; data not shown). Thus, cells in the PPN domain express So, Dac, and Eya as well as Tsh, Ey, and Hairy. Anterior to the PPN domain there is a gradual transition into domain II, where cells express Hth, Ey, and Tsh, but not So, Eya, Dac, or Hairy (Fig. 1I).

In late second/early-third-instar eye discs, before or just as the MF is initiated, most eye disc cells express tsh, hth, and ey, although the levels of Hth are lower close to the posterior margin (Fig. 1H). Therefore, at this stage of development most eye disc cells express the same combination of transcription factors as domain II of third-instar discs. In both cases, these cells are uncommitted and dividing asynchronously (Wolff and Ready 1991).

Interaction and cross-regulation among hth, ey, and tsh

The overlapping expression patterns of $e y, h t h$, and $t s h$ in domain II raised the possibility that their gene products could be functioning together. As a first test of this idea, we determined if their protein products can interact with each other in vitro and in vivo. We found that histidine (his)-tagged Hth, alone or together with its partner protein Extradenticle (Exd; Rieckhof et al. 1997; Mann and Affolter 1998), specifically binds to ${ }^{35}$ S-labeled Ey and Tsh in vitro (Fig. $2 \mathrm{~A}-\mathrm{C}$ ). In vivo, we found that both Exd and Tsh could be coimmunoprecipitated (IP) from wild-type embryos with Hth (Fig. 2D; data not shown). 
We have been unable to coimmunoprecipitate Ey and Hth from wild-type embryos, perhaps because the num-

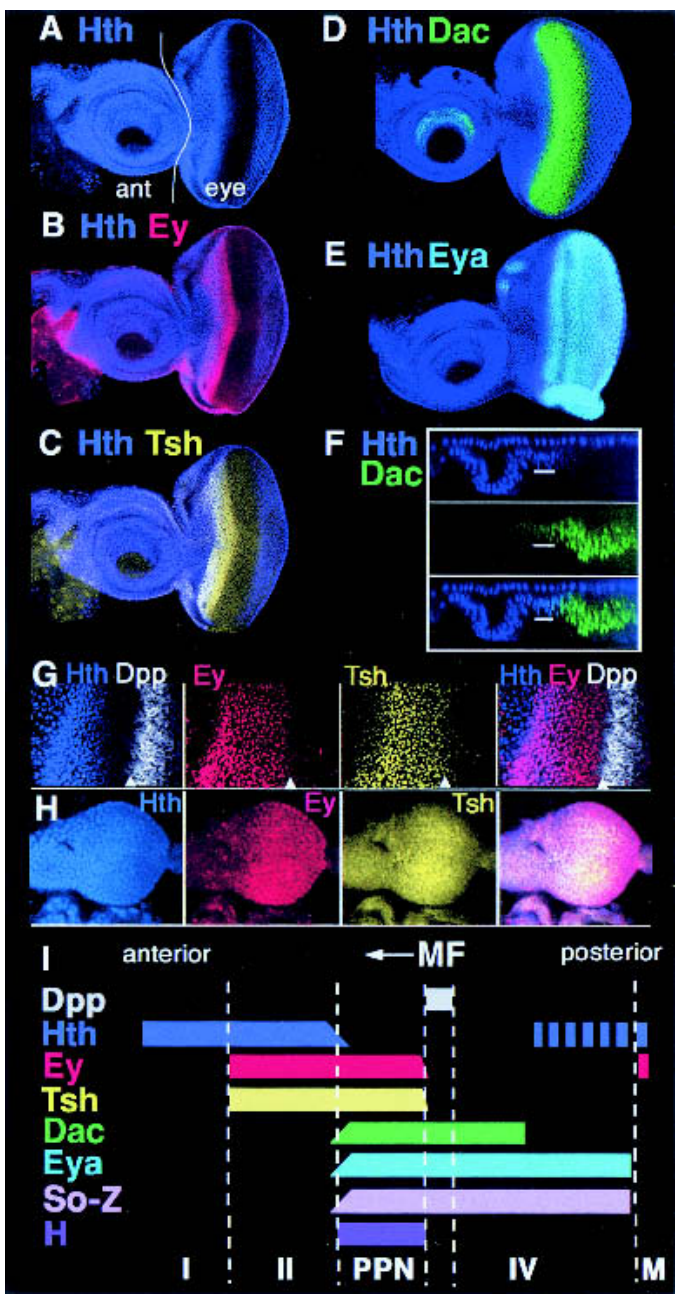

Figure 1. Transcription factor expression domains in the eye imaginal disc. All images are of wild-type eye-antennal discs. Anterior is to the left. $(A-E)$ Eye-antennal discs stained for $(A)$ Hth, (B) Hth + Ey, (C) Hth + Tsh, (D) Hth + Dac, and $(E)$ Hth + Eya as indicated. In $A$ the antennal (ant) and eye portions of the disc are indicated. (F) An optical cross-section of a disc stained for Hth and Dac, showing the reciprocal relationship between these two factors in the main epithelium of the eye disc. Eya and Hth have a similar relationship (data not shown). The upper row of Hth-positive nuclei are in the peripodial membrane. $(G)$ Closeup of the anterior region of a disc stained for Hth, Ey, Tsh, and dpp-lacZ. The arrowheads point to the anterior edge of the MF, as marked by dpp-lacZ expression. Although Tsh and Ey are not expressed posterior to the furrow, some background signal is observed in these images. $(H)$ Secondinstar eye-antennal discs stained for Hth, Ey, and Tsh. Ey is expressed evenly throughout the eye disc. Hth and Tsh are also expressed in all cells, but at lower levels posteriorly. (I) A summary of these expression patterns. The expression domains of Hairy $(\mathrm{H})$ and Dpp are also summarized. The So- $\mathrm{Z}$ pattern is based on a lacZ enhancer trap into so (data not shown). Based on these patterns, the following domains can be defined: domain I (Hth, alone); domain II (Hth, Tsh, Ey); PPN (Tsh, Ey, So, Eya, Dac, H); domain IV (So, Eya, Dac); MF (morphogenetic furrow); and $\mathrm{M}$ (margin cells, Hth, Ey). ber of cells coexpressing these transcription factors is too few. These results suggest that Hth, Exd, Tsh, and Ey have the potential to interact with each other in vivo. However, additional experiments are required to definitively test this idea.

We also tested if these factors can regulate each other's expression in the eye disc. We generated clones of cells that express the yeast transcription factor Gal4 in flies containing UAS-Ey, UAS-Hth, or UAS-Tsh transgenes. These clones were generated during the second instar, when all three of these genes are coexpressed throughout the eye disc (Fig. 1H), and analyzed during the third instar, when the Hth expression pattern is distinct from the Tsh and Ey expression patterns. Tsh or Ey overexpressing clones in the PPN domain up-regulate Hth (Fig. 2E,F). The ability to maintain Hth expression was limited to the PPN domain; Ey- or Tsh-expressing clones within or posterior to the MF did not alter Hth expression. We also found that Hth could maintain Ey and Tsh expression posterior to its normal expression domain (Fig. 2G; data not shown). Although this effect was not limited to the PPN domain, it was only observed in $\sim 50 \%$ of the clones generated during the second instar, suggesting that other factors or the timing of clone induction limit this response. In addition, ectopic Tsh can also induce Ey expression in a subset of the eye imaginal disc (Pan and Rubin 1998). Together with the protein interaction experiments, the ability of these transcription factors to maintain or induce each other's expression suggests that these proteins may function together in eye development.

We note that expression of Tsh or Ey maintains Hth expression in the PPN domain, where Tsh and Ey are already expressed. We interpret this result as suggesting that $h t h$ is under two competing controls: maintenance by Tsh and Ey and repression by other factors, in particular the Dpp pathway (see below), and that expressing higher levels of Tsh or Ey can shift this balance in favor of maintenance.

\section{hth, but not tsh or ey, is repressed by Dpp}

The patterns of Tsh, Ey, and Hth expression in the anterior of the eye disc suggest that $h t h$ is repressed by a signal coming from the MF. A good candidate for this signal is Dpp because it can act at long range ahead of the furrow (Chanut and Heberlein 1997; Pignoni and Zipursky 1997; Greenwood and Struhl 1999). We tested this idea in two ways. First, we eliminated the activity of the Dpp pathway in clones of cells mutant for its downstream transcription factor, mothers against Dpp (mad; Sekelsky et al. 1995; Wiersdorff et al. 1996). We found that $\mathrm{mad}^{-}$clones de-repress $h t h$, consistent with the idea that Dpp represses $h t h$ (Fig. 3A,B). De-repression of $h t h$ was observed in $\mathrm{mad}^{-}$clones that touched the posterior margin of the eye disc as well as in clones within the PPN domain. However, $\mathrm{mad}^{-}$clones close to the MF only partially de-repressed $h t h$, suggesting that other signals present in the MF and acting at short range can also repress $h t h$. One such signal may be $H h$, which is suffi- 
Bessa et al.

Figure 2. In vitro and in vivo interactions among Ey, Hth, and Tsh. $(A-C)$ In vitro interaction experiments. (A) ${ }^{35} \mathrm{~S}$-Ey, $(B){ }^{35} \mathrm{~S}$-Tsh, or $(C){ }^{35} \mathrm{~S}$-Luciferase proteins pulled down with empty beads (lane 2), an Hth/Exd dimer (lane 3), Hth alone (lane 4), Exd alone (lane 5), or CG9403, a zinc-finger protein that serves as a negative control (lane 6). The input for each ${ }^{35} \mathrm{~S}$ protein is shown in lane 1. $(D)$ Total embryo extracts were immunoprecipitated with either preimmune sera (pre) or anti-Hth sera $(\alpha H$ th), run on an SDS-PAGE gel, and probed with an anti-Tsh antibody. A total embryonic lysate shows the position of Teashirt (lysate). (E-G) The MF region of eye discs containing clones of cells expressing Ey $(E)$, Tsh $(F)$, or Hth $(G)$. Anterior is to the left, and the red arrowheads point to the approximate position of the $M F$. Clones are marked by the absence of GFP (green) and were stained for Hth $(E, F)$ or Ey $(G)$. White arrows point to regions that show ectopic expression and pink arrows point to regions that do not show ectopic expression.

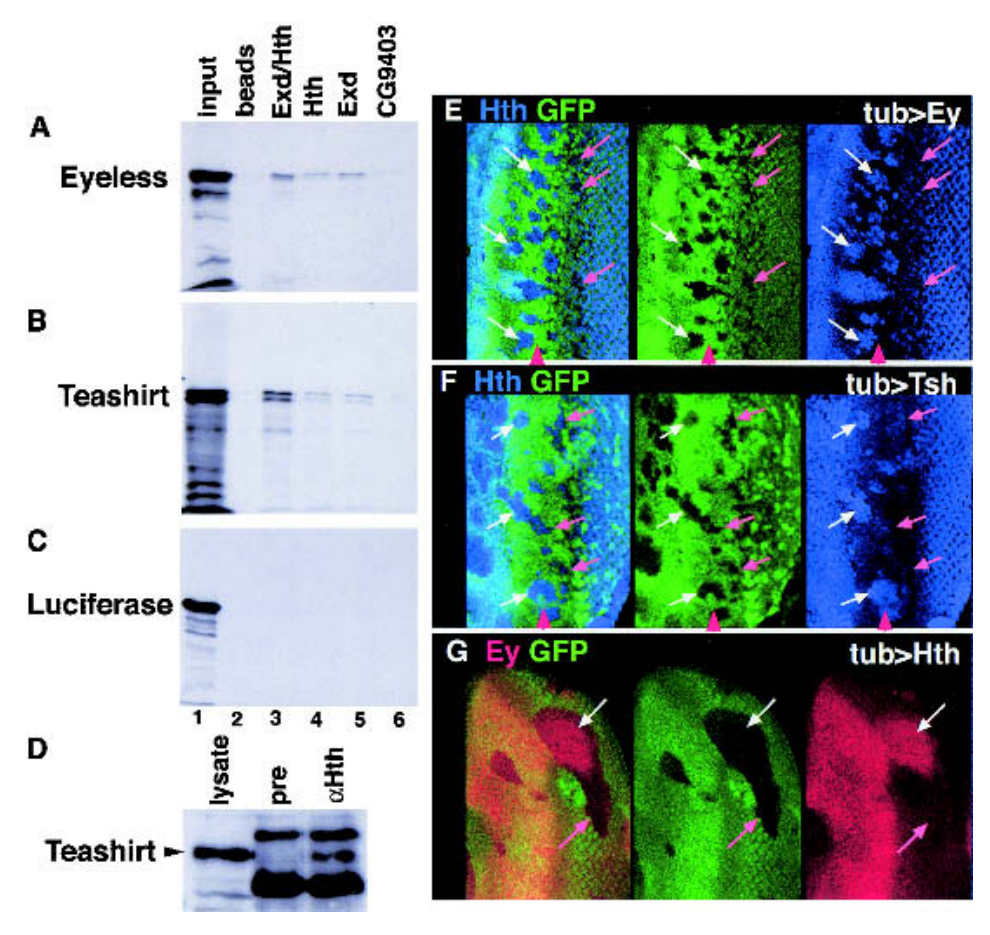

cient for furrow propagation in the absence of Dpp signaling (Burke and Basler 1996; Wiersdorff et al. 1996).

The de-repression of $h t h$ in $\mathrm{mad}^{-}$clones suggests that Dpp, expressed from the MF, acts at long range to repress $h t h$. In contrast, $t s h$ and $e y$ are expressed in cells adjacent to the MF (Fig. 1), suggesting that these genes are not as sensitive to repression by Dpp. To test this directly, we activated the Dpp pathway in clones of cells by expressing an activated form of the Dpp receptor, Thick veins $\left(\mathrm{Tkv}^{\star}\right.$; Nellen et al. 1996). Expression of $\mathrm{Tkv}^{\star}$ completely repressed $h t h$, but failed to repress ey (Fig. 3C,D). tsh was also not repressed in most $\mathrm{Tkv}^{\star}$ clones. However, tsh expression was reduced in some clones, suggesting that high levels of Dpp activity may be able to repress tsh (Fig. 3C,D; data not shown). The complete repression of $h t h$, but not ey or $t s h$, by $\mathrm{Tkv}^{\star}$ is consistent with the idea that Dpp represses $h t h$, but not ey or tsh, as the MF moves anteriorly. Because ey and tsh are also repressed as the MF moves, there must be another signal coming from the furrow that acts at short range to repress these genes. This signal could be $\mathrm{Dl}, \mathrm{Hh}$, or a third, as-yet unidentified, signal (Greenwood and Struhl 1999; Baonza and Freeman 2001).

The complementary patterns of Hth versus So, Eya, and Dac at the transition between domain II and the PPN domain suggested that these factors may also be playing a role in $h t h$ repression. To test this idea, we examined clones of cells mutant for eya. ey $a^{-}$clones de-repress $h t h$ (Fig. 4B). Part of this de-repression is probably due to the fact that $d p p$ expression requires eya (Hazelett et al. 1998). However, the de-repression of $h t h$ is observed in all ey $a^{-}$cells, even in cells that are next to wild-type, $d p p$-expressing cells (Fig. 4C). Thus, Dpp expressed in wild-type neighboring cells is not able to repress $h t h$ in
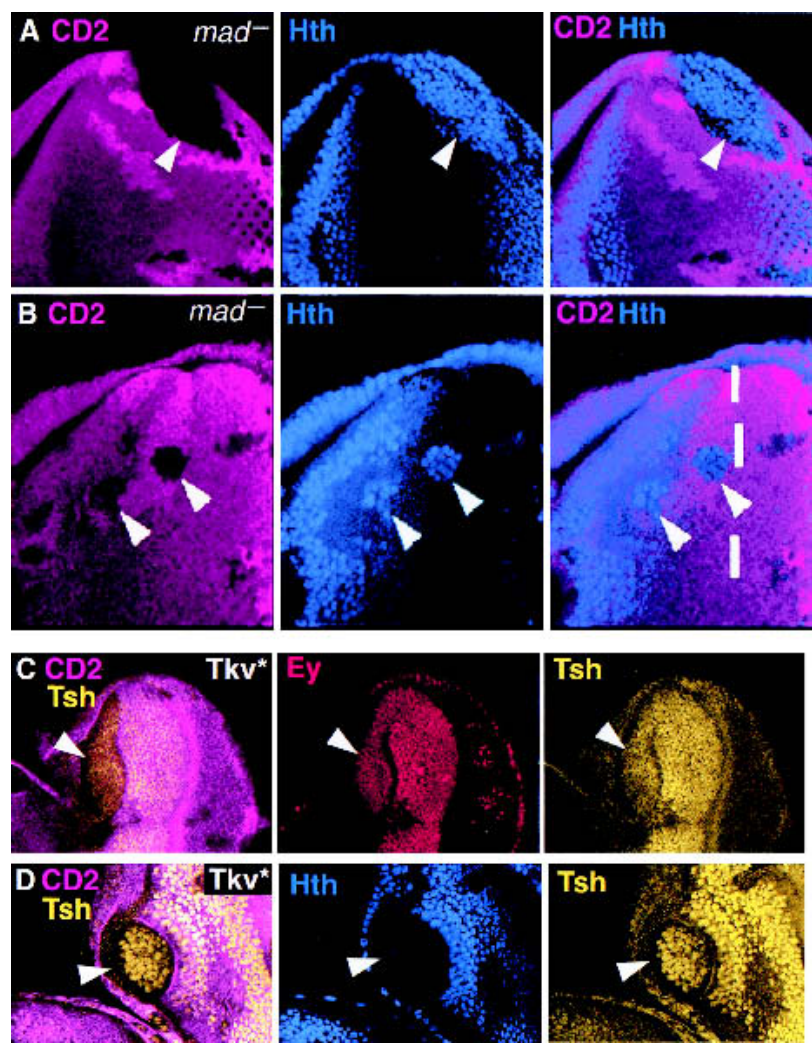

Figure 3. hth, but not ey or tsh, is repressed by Dpp in the eye disc. $(A, B) \mathrm{mad}^{-}$clones, marked by the absence of CD2 (fucsia), stained for Hth (blue). Arrowheads point to clones. The dashed line in $B$ marks the approximate position of the MF. $(C, D)$ Clones expressing $\mathrm{Tkv}^{\star}$, marked by the absence of CD2 (fucsia) and stained for $(C)$ Tsh + Ey or $(D)$ Tsh + Hth. 
adjacent eya $a^{-}$cells. These data suggest that eya is required for Dpp to repress $h t h$ in the PPN domain. hth was also de-repressed in $d_{a c^{-}}$clones (data not shown), suggesting that dac also plays a role in $h t h$ repression.

\section{Repression of hairy and the PPN domain by Hth}

In wild-type eye discs, the anterior edge of the PPN domain, as defined by hairy expression, abuts the posterior edge of Hth expression (Fig. 5A,B). This observation suggests that hairy, which is an activated target of Dpp ahead of the MF (Brown et al. 1995; Greenwood and Struhl 1999; Baonza and Freeman 2001), might be repressed by Hth. In support of this idea, ectopic Hth expression represses hairy (Fig. 5C). In addition, in some, but not all, anterior $h t h^{-}$clones hairy was de-repressed (data not shown). These data suggest that the anterior limit of the PPN domain, defined by hairy expression, is controlled by hth.

\section{Repression of eya and dac by Hth, Ey, and Tsh}

In contrast to the clear repression of hairy by $\mathrm{Hth}$, in most cases ectopic expression of $\mathrm{Hth}$ was unable to repress dac or eya (Fig. 6A). Similarly, ectopic expression of Tsh was also generally unable to repress these genes

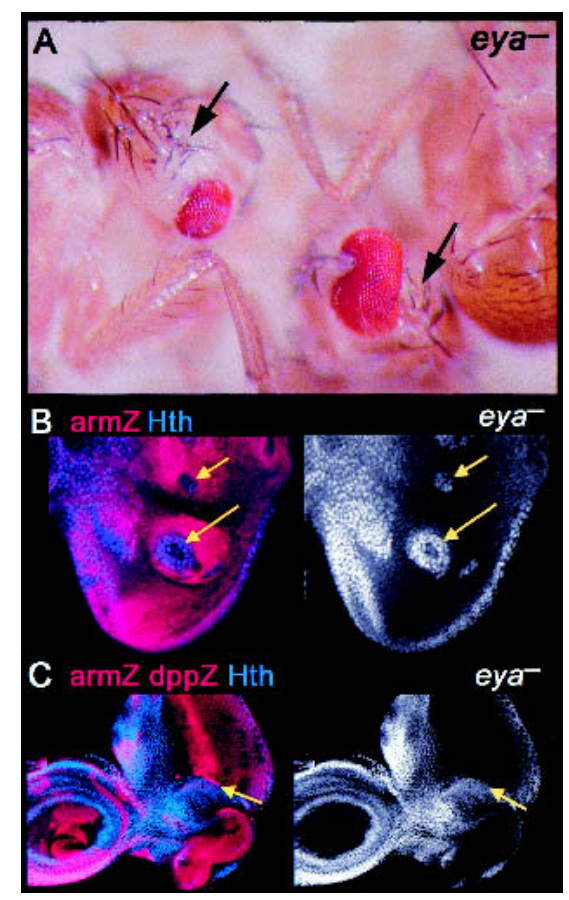

Figure 4. eya represses $h t h$ and head capsule development. $(A)$ Adult flies containing ey $a^{-}$clones. Although eya $a^{-}$tissue is unmarked, these heads show a loss of eye and a corresponding increase in head capsule (arrows). $(B, C)$ ey $a^{-}$clones, marked by the absence of arm-lacZ (red), stained for Hth (blue in left panels and white in right panels). Hth is de-repressed cell-autonomously in ey $a^{-}$cells. In $C$, the disc also expresses dpp-lacZ (strong red stripe). Hth is de-repressed in $e y a^{-}$cells, even when they are adjacent to Dpp-expressing cells (yellow arrows in $C$ ).

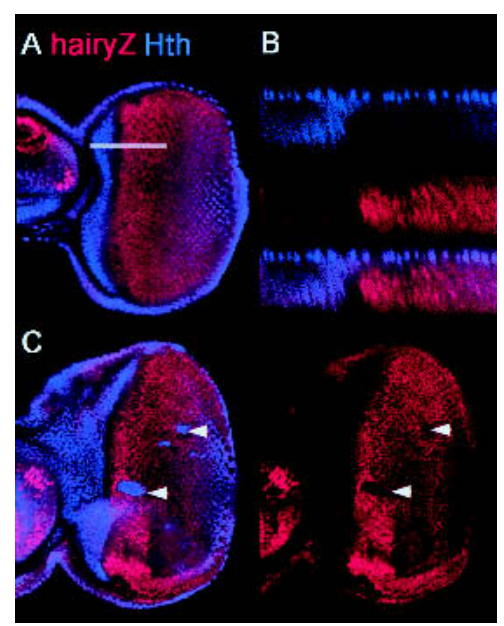

Figure 5. Hth represses hairy. (A) Wild-type eye disc stained for Hth (blue) and Hairy-lacZ (red). Note that Hairy-lacZ is observed more posteriorly than Hairy because of persistence of $\beta$-galatosidase (data not shown). (B) An optical cross-section of a wild-type disc (at the position of the white line in $A$ ), showing no overlap between Hth and Hairy. $(C)$ Ectopic clones of Hth (arrowheads), stained for Hth (blue) and Hairy-lacZ. Hth represses Hairy-lacZ expression.

(Fig. 6B). The few cases in which we observed repression of eya by Tsh or Hth were in the PPN domain, which, significantly, is where these transcription factors are able to maintain each other's expression (Fig. 2; data not shown). In contrast, repression of eya or dac was not observed in clones expressing Tsh or Hth posterior to the MF.

Because Hth is coexpressed and can interact in vitro with Tsh and Ey, we considered the possibility that combinations of these transcription factors might be required to repress eya and dac. Consistent with this idea, we found that the simultaneous expression of Tsh and Hth efficiently repressed eya and dac expression (Fig. 6C; data not shown). Importantly, the dual expression of Tsh and Hth maintained Ey expression (Fig. 7F); consequently, these clones expressed all three of these transcription factors. We also tested other pairs of these transcription factors (Hth + Ey and Tsh + Ey) and found that they could also partially repress eya (data not shown).

The above results suggest that the combination of $\mathrm{Hth}+\mathrm{Ey}+\mathrm{Tsh}$, which is normally present in domain II, is able to repress the expression of eya. To test if $h t h$ normally plays a role in the repression of these genes, we examined $h t h^{-}$clones. Although $h t h^{-}$clones anterior to the MF are rare (see below), we found that both dac and eya were de-repressed in anterior $h t h^{-}$clones (Fig. 6D; data not shown).

In summary, these data suggest that the combination of the factors expressed in domain II is necessary and sufficient to repress eya and dac. In contrast, Hth is sufficient to repress the pre-proneural gene hairy. Conversely, eya and dac, together with Dpp, repress $h t h$ as the MF advances. We suggest that one function for this reciprocal antagonism may be to prevent premature and 
Figure 6. $\mathrm{Ey}+\mathrm{Hth}+\mathrm{Tsh}$ represses eya. $(A)$ Clone of ectopic GFP-Hth in an eye disc (arrowhead) stained for Hth (blue) and Eya (red). No repression of Eya is observed. (B) Clones of ectopic Tsh, marked by the absence of GFP, in an eye disc stained for Eya (red). No repression is observed (arrowheads). The * marks an overgrowing clone in the peripodial membrane in a different focal plane that causes a distortion of the eye disc epithelium. $(C)$ Clones of ectopic Tsh + GFP-Hth stained for GFP (white) and Eya (red). Repression of Eya is observed (arrowheads). (D) $h t h^{-}$clones, marked by the absence of GFP, stained for Eya. De-repression of Eya is observed (arrowheads). De-repression of dac is also observed in $h t h^{-}$ clones (data not shown).
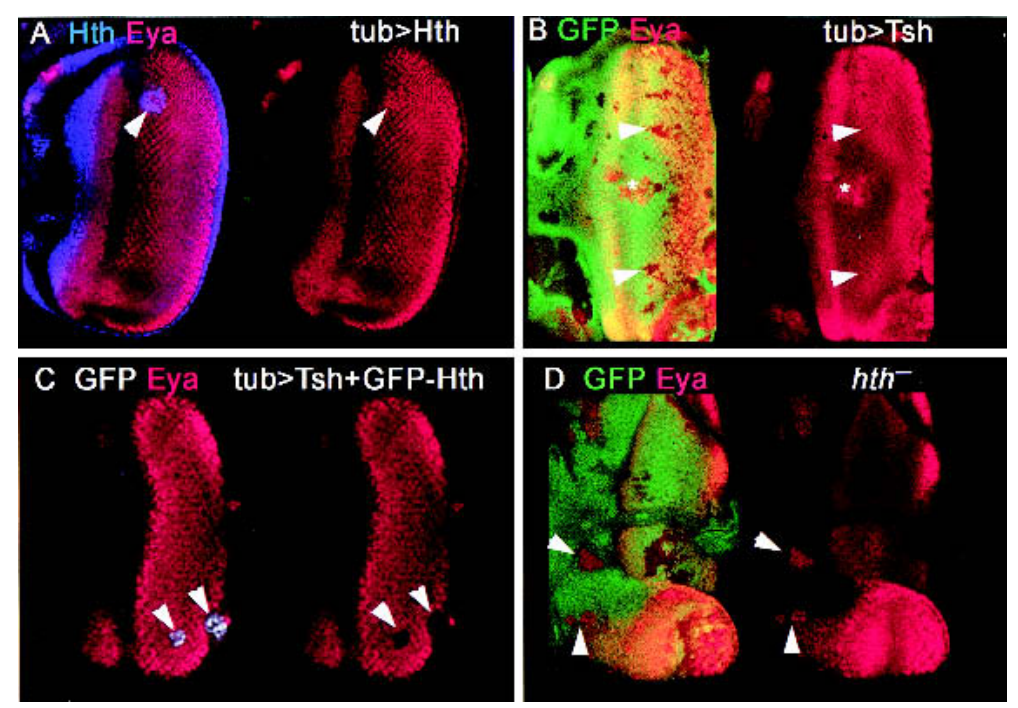

uncoordinated differentiation anterior to the MF. However, as the MF advances, $h$ th must be repressed to allow differentiation to occur.

\section{Control of eye disc growth by hth, ey, and tsh}

Another function for $h t h, e y$, and tsh may be in promoting cell proliferation. Most of the growth of the eye imaginal disc occurs via asynchronous cell divisions throughout young discs, before the MF initiates, as well as in cells anterior to the MF in older discs. $h t h, t s h$, and ey are coexpressed with each other in both cases. Immediately anterior to the MF, cell divisions become synchronous, and in the MF, cells are arrested in the $G_{1}$ phase of the cell cycle (Wolff and Ready 1991; Baker and Yu 2001). Posterior to the MF, some cells exit the cell cycle and differentiate into photoreceptors, whereas all other cells undergo one more mitosis before differentiating into accessory cells or being eliminated by apoptosis (Wolff and Ready 1991; Baker and Yu 2001). dpp, which represses $h t h$ as the furrow advances, is required for this cell cycle coordination (Horsfield et al. 1998). From these observations and the data described below, we suggest that the anterior factors may play an important role in promoting cell proliferation in the eye disc.

As a first test of this idea, we examined the frequency of $h t h^{-}$clones compared with the frequency of neutral clones in the eye disc. We generated $h t h^{-}$clones using ey-flp, which provides a source of the yeast recombinase Flp throughout most of eye disc development (see Materials and Methods). In this experiment, clones have the potential to be generated at all times during development. Neutral clones were observed at all positions in the eye disc, and varied in size, consistent with the idea that they could be formed throughout development (Fig. 7A). In contrast, although $h t h^{-}$clones were readily observed posterior to the MF, they were only rarely observed anterior to the MF (Fig. 7B). The reciprocal mitotic recombination products (twin spots) were observed in the anterior, suggesting that $h t h^{-}$cells were generated but were unable to grow in that region of the eye disc. We suggest two explanations for this observation. First, $h t h^{-}$cells, which begin to express eya and dac (see above), might grow poorly and be outcompeted by neighboring wild-type cells. Second, some $h t h^{-}$cells might migrate posteriorly, into the domain in which $h t h$ is normally turned off. Regardless of the explanation, these observations suggest that $h t h^{-}$cells do not proliferate well in this region of the eye disc. In contrast, because $h t h^{-}$clones are observed posteriorly, there may be a time when $h t h$ function is no longer required for cells to proliferate, but before cells exit from the cell cycle. This window could exist within the PPN domain.

We also observed dramatic differences in the growth of clones ectopically expressing Tsh, Ey, Hth, or combinations of these factors. Clones that misexpress Tsh in differentiated cells (posterior to the MF) are very small, suggesting that they do not alter the growth properties of these cells. Ectopic Tsh-expressing clones also survive poorly anterior to its normal expression domain (Fig. 7E). In contrast, clones expressing only Hth, only Ey, or $\mathrm{Hth}+$ Tsh grow larger than the clones expressing Tsh alone (Fig. 7F; data not shown). Thus, forcing the expression of these transcription factors prevents these cells from exiting the cell cycle as they usually would in response to signals in the MF.

Most dramatic, however, is the growth of clones that arise at the posterior or lateral margins of the eye disc. In wild-type eye discs, these margin cells express $h t h$ and ey, but not tsh (Fig. 7C; data not shown). When Tsh or $\mathrm{Hth}+\mathrm{Tsh}$ are misexpressed in margin cells, the clones can grow to be very large (Fig. 7E,F). Similar overgrowths are produced in clones expressing these factors in peripodial membrane cells (data not shown). We also observe similar overgrowths at a lower frequency when the clones misexpress Hth in margin cells. However, whenever we observe an overgrowing clone at the edge of the disc, the cells invariably express Hth, Tsh, and Ey (Fig. 7; data not shown). Curiously, these overgrowths also express eya, suggesting that Hth, Tsh, and Ey induce pro- 

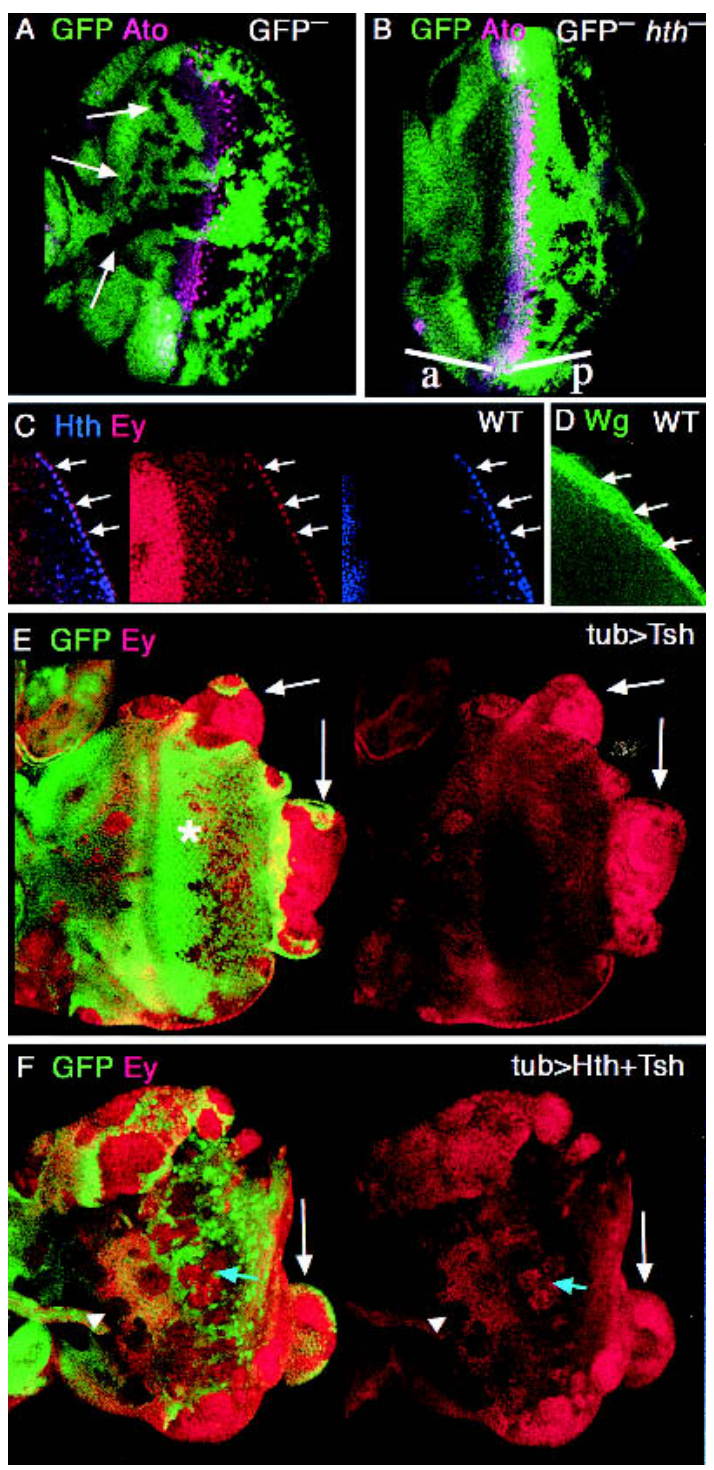

Figure 7. Genetic control of proliferation of the eye disc. $(A, B)$ Neutral $(A)$ or $h t h^{-}(B)$ clones, marked by the absence of GFP, and stained for the MF marker, Ato (fuchsia). Neutral clones are observed both anterior (arrows) and posterior to the MF. $h t^{-}$ clones are only rarely observed anterior (a) to the MF but are readily observed posterior $(\mathrm{p})$ to the furrow. $(C)$ Detail of the posterior margin of a wild-type eye disc stained for $\mathrm{Hth}$ (blue) and Ey (red). Hth and Ey are both expressed in these cells (arrows). Tsh is not expressed in these cells (data not shown). (D) Similar region of a wild-type disc stained for $\mathrm{Wg}$ (green), which is expressed in margin cells. $(E, F)$ Clones of cells expressing $(E)$ Tsh or $(F)$ Tsh + Hth, marked by the absence of GFP, stained for Ey (red). (E) Tsh clones grow poorly in the middle of the disc $\left({ }^{\star}\right)$ but can induce large overgrowths at the edge of the disc (arrows). Overgrowing clones, but not internal clones, express Ey. $(F)$ Tsh + Hth clones grow well in the middle of the disc (blue arrow) and also induce overgrowths at the edge of the disc (white arrow). Most clones maintain Ey expression, although some anterior clones show repression of Ey (arrowhead).

liferation, but are unable to repress eya in these overgrowing margin cells. Similar overgrowths have also been observed when the wingless ( $w g$ ) pathway is activated (e.g., in axin ${ }^{-}$clones; Lee and Treisman 2001; data not shown), suggesting that wingless is also playing a role in the aberrant growth properties of these cells. Consistent with this idea, margin cells also express $w^{g}$ (Fig. 7D; Baker 1988; Ma and Moses 1995).

Ectopic eyes are induced in hth- and tsh-expressing regions of the wing disc

The above results suggest that an Ey-Hth-Tsh complex functions in the eye disc to permit cell proliferation and repress the expression of the later-acting transcription factors $\mathrm{H}$, Eya, So, and Dac. How important is this anterior combination of transcription factors for eye development? As hth is expressed together with ey in very early imaginal discs, it is not possible to remove $h t h$ early enough to address this question in the eye disc, itself. Moreover, removing $h t h$ during the second instar induces ectopic eye development in the ventral head, through a loss of wingless expression at the ventral margin of the eye disc (Pai et al. 1998; Pichaud and Casares 2000). Thus, in addition to the functions defined here, $h$ th also limits eye development ventrally. This function, together with the early expression of $h t h$ in young eye discs, complicates the ability to determine if there is an absolute requirement for $h t h$ ahead of the MF.

Instead of removing hth function from the eye disc, we used the potent ectopic eye-inducing function of Ey to assess how critical hth is for eye development. If $h$ th is required for Ey to induce ectopic eyes, we would expect to observe a strong bias for where, in the body, ectopic eyes are generated. Consistent with this prediction, when Ey is expressed via several different Gal4 driver lines in the wing imaginal disc (see Materials and Methods), ectopic eye tissue is induced predominantly in the wing hinge, where hth is most highly expressed (Fig. 8; data not shown). tsh is also expressed in the wing hinge, and its expression pattern overlaps that of hth (Azpiazu and Morata 2000; Casares and Mann 2000). As in normal eye development, hth expression is repressed in the ectopic eye tissue. The correlation between where ectopic eyes are formed and where $h t h$ and tsh are expressed supports the idea that $h t h$ and tsh cooperate with ey to promote eye development.

\section{Discussion}

Previous work on Drosophila eye development has focused on the complex signaling events that occur just anterior, within, and posterior to the MF. The canonical view posits that as the MF moves anteriorly, undifferentiated cells ahead of the furrow are recruited to become either photoreceptors or accessory cells. The experiments presented here shed new light on the nature and function of the cells anterior to the MF. We define two domains anterior to the hairy-expressing PPN domain (Greenwood and Struhl 1999; Baonza and Freeman 2001). One of these domains (II) expresses three transcription 
Figure 8. Induction of ectopic eyes in the hinge region of wing discs. $(A, B)$ Wing imaginal disc in which Ey was

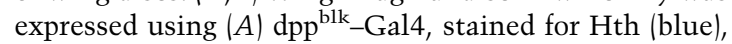
Elav (green), and Distalless (Dll; red); $(B)$ only the Hth and Dll channels are shown. dpp ${ }^{\text {blk_}}$ Gal4 is expressed in a dorsal-to-ventral stripe across the entire wing disc just anterior to the AP compartment boundary. Wing discs have four main regions: (1) notum, (2) dorsal hinge, (3) wing pouch, and (4) ventral hinge. Hth is expressed in regions 1,2 , and 4 , but not in 3 . Tsh is expressed in regions 1, 2, and 4 also. Ectopic eye tissue, as detected by Elav, is observed in regions 1,2 , and 4 (arrows), but not
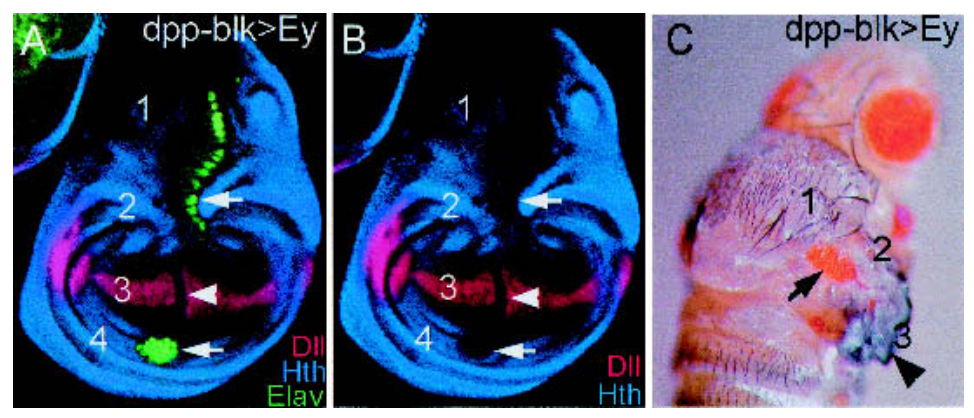
in 3 (arrowhead). Dll and Hth are repressed by Ey expression in regions 1, 2, 3, and 4. dpp ${ }^{\text {blk }}$-Gal4; UAS-ey also generates ectopic eyes in the proximal leg disc (data not shown). A similar correlation between ectopic Elav and Hth + Tsh expression was observed with

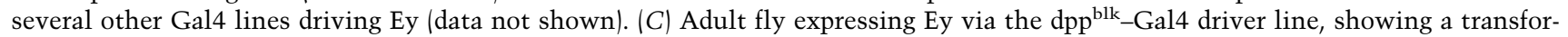
mation of the hinge to eye (arrow). Wing blade development is partially suppressed in these flies, although wing tissue is still formed (arrowhead).

factors: Ey, which was already known to play a central role in eye development (Halder et al. 1995); Hth, which also plays a role in suppressing eye development in the ventral head (Gonzalez-Crespo and Morata 1995; Pai et al. 1998; Pichaud and Casares 2000); and Tsh, which, because of its ability to induce ectopic eyes elsewhere in the head (Pan and Rubin 1998), was also implicated in eye development. Our results suggest that, although these cells have not committed to become a particular cell type, they are predisposed to become eye tissue. Furthermore, we suggest that the combination of Hth, Ey, and Tsh performs at least two functions during eye development: it represses the expression of later-acting transcription factors in the eye development cascade, and it promotes cell proliferation. Below, we discuss each of these points and integrate our findings with the current view of eye development (Fig. 9).

\section{hth defines the anterior limit of the PPN domain}

The definition of the PPN domain stems from the observation that the induction of neural cell fates in the eye disc requires at least two signals downstream of $\mathrm{Hh}$. The first signal is Dpp, which creates a zone of cells ahead of the MF, termed the PPN domain, which is competent to receive a second, proneural-inducing signal (Greenwood and Struhl 1999; Baonza and Freeman 2001). Cells in the PPN domain express high levels of hairy. Only cells that receive the Dpp signal are able to respond to the second, shorter-acting signal. This second signal is $\mathrm{Dl}$, which is expressed by cells in and behind the furrow and is required for the down-regulation of hairy (Baonza and Freeman 2001). In addition to $\mathrm{Dl}$, neural induction, in particular the initiation of ato expression, may also require another signal that is transduced by the ser/thr kinase raf (Greenwood and Struhl 1999).

We have linked $h$ th to the PPN domain in three ways. First, in wild-type eye discs, hth expression abuts hairy expression. Second, Hth represses hairy. These data suggest that $h t h$ defines the anterior limit of hairy expression. Third, Dpp is a repressor of $h t h$. Together, these results suggest that the anterior limit of the PPN domain is defined by $h$ th expression, and that, as the MF moves anteriorly, hth is repressed by Dpp, allowing the PPN domain and hairy expression to shift anteriorly. In our experiments, only some anterior $h t h^{-}$clones de-repressed hairy. We interpret this result as suggesting that hairy expression is both activated by Dpp and repressed by $h t h$. Consequently, $h t h^{-}$cells that do not receive enough Dpp would still be unable to express hairy.

In the absence of Dpp signaling, the MF is still able to progress across the eye disc because other signals, such as Hh, are sufficient for furrow progression (Burke and

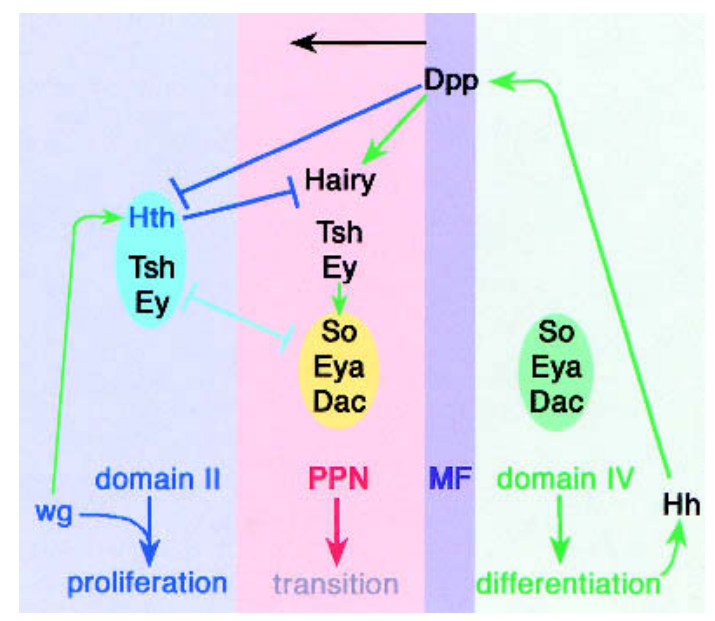

Figure 9. Summary. The factors and their interactions present in domains II, IV, PPN, and the MF are schematized. Do main IV expresses the differentiation transcription factors So, Eya, and Dac. Differentiated cells also express Hh, which induces Dpp expression in the MF. Dpp represses Hth and induces Hairy. Hth represses Hairy. The combination of Hth-Tsh-Ey is mutually antagonistic with So-Eya-Dac. Ey also directly activates So expression (Niimi et al. 1999), perhaps in the PPN domain. Also indicated is a positive requirement for $\mathrm{Wg}$ signaling for $\mathrm{Hth}$ expression in domain II (data not shown). Wg, together with the factors present in domain II, is proposed to promote proliferation in the eye disc. Not indicated here is our observation that Eya and Dac collaborate with Dpp to repress Hth and our inference that an unknown short-range signal in the MF represses Tsh and Ey. 
Basler 1996; Wiersdorff et al. 1996; Chanut and Heberlein 1997; Greenwood and Struhl 1999). This is consistent with our inference that other short-range signals present in the MF can also repress $h t h$. However, the furrow moves more slowly when it confronts cells that cannot respond to Dpp. The slower progression of the furrow could, in part, be because these cells express Hth. Interestingly, Dpp is not expressed in the MF during retinal morphogenesis in the beetle Tribolium or the grasshopper Schistocerca (Friedrich and Benzer 2000). The use of $d p p$ in eye development may have been necessary in faster-growing insects like Drosophila to increase the speed of eye morphogenesis. Cells at the lateral and posterior edges of the Drosophila eye disc and in the far anterior of the disc continue to express $h t h$ and contribute to non-eye portions of the adult head (Bryant 1978; Casares and Mann 1998; Pichaud and Casares 2000). Moreover, ey $a^{-}$eye disc cells continue to express $h t h$ and contribute to non-eye regions of the head (Fig. 4). Taken together, these observations suggest that changing the potency of Dpp's ability to repress $h t h$ could be used as a way to both modulate the pace of eye development and to control the ratio of eye-to-head tissue.

\section{Mutual antagonism between anterior and posterior transcription factors}

Our experiments suggest that one of the functions mediated by Ey-Hth-Tsh is to repress eya and dac (Fig. 9). This proposal stems from both ectopic expression experiments, showing that the coexpression of Ey, Hth, and Tsh represses these genes, and from loss-of-function experiments, showing that $h t h^{-}$clones anterior to the MF de-repress these genes. Similarly, $h t h$ is de-repressed in both ey $a^{-}$and $d_{a c^{-}}$clones, suggesting that this antagonism exists in both directions. Interestingly, the antagonism between these two sets of genes is analogous to that observed in other appendages. In the leg, $h t h$ and $t s h$ are required for the development of proximal fates, and have been shown to be mutually antagonistic with dac and Distal-less (D11), two genes required for intermediate and distal leg fates, respectively (Mardon et al. 1994; Gonzalez-Crespo and Morata 1995; Abu-Shaar and Mann 1998; Gonzalez-Crespo et al. 1998; Wu and Cohen 1999). Similarly, in the wing, $h t h$ and $t$ sh are required for proximal wing fates, and oppose the activity of vestigial ( $\mathrm{vg}$ ), which is required for more distal wing fates (Azpiazu and Morata 2000; Casares and Mann 2000; Wu and Cohen 2002).

\section{Control of eye disc growth by Ey-Hth-Tsh}

We propose that the putative Ey-Hth-Tsh complex promotes cell proliferation in early eye discs and in cells anterior to the PPN domain in third-instar discs. This suggestion is based on three observations. First, in young discs, when most of the growth of the eye disc occurs and before the MF initiates, all eye disc cells express all three of these transcription factors. Second, $h t h^{-}$clones are only rarely observed anterior to the MF. The lack of $h t h^{-}$ clones observed in this region of the eye disc suggests that $h t h$ is playing an important role in either the survival or proliferation of these cells.

A third reason for linking this combination of transcription factors with the growth of the eye disc stems from our observation that, when coexpressed, these factors can induce cell proliferation. This was most readily observed in clones that include cells at the edge of the eye disc. These cells may be unique in the eye disc because they express wg (Fig. 7D; Baker 1988; Ma and Moses 1995; Treisman and Rubin 1995). Interestingly, activation of the $w g$ pathway by generating axin $^{-}$clones in the eye disc also induces proliferation and the maintenance of $e y, h t h$, and $t$ sh expression (Lee and Treisman 2001; data not shown). Thus, proliferating eye disc cells express $h t h, e y$, and $t s h$ and are in a state in which the wg pathway is activated (Fig. 9). We speculate that this state, which can be induced by the expression of Tsh, Ey, and Hth at the edge of the eye disc, mimics the normal state of eye disc cells during the second instar, when the disc is growing most rapidly. Consistent with this idea, anterior $h t h$ expression in the eye disc is autonomously lost in dishevelled $d^{-}\left(d s h^{-}\right)$clones, showing that these cells require $w g$ signaling to maintain their anterior identity (Fig. 9; data not shown).

Our experiments have not addressed the mechanism by which Ey-Hth-Tsh promotes cell proliferation. One possibility is that these factors do so directly, for example, by regulating the expression of genes that control the cell cycle or cell growth. Alternatively, these factors may promote proliferation indirectly, for example, by repressing genes, such as eya, that are required for differentiation and exit from the cell cycle. In either case, the model predicts that there should be a similar requirement for ey and $t s h$ in eye disc proliferation as we have described for $h t h$. Although it is not presently possible to generate $e y^{-}$clones, ey has been suggested to be required for cell survival in the early eye disc, a result that is consistent with our conclusions (Kronhamn et al. 2002). Pan and Rubin (1998) have reported that $t s h^{-}$clones survive and differentiate normally in the adult eye and, based on this observation, suggested that tsh does not play an essential role in eye development. However, because of technical limitations in inducing large numbers of $t s h^{-}$clones, their frequencies in different regions of the eye disc have not been examined. The survival of $t s h^{-}$clones in the adult eye may be analogous to the survival of $h t h^{-}$clones that we observe posterior to the MF. Therefore, it is possible that tsh and ey are also important for the survival and/or growth of cells anterior to the MF. A definitive test of this idea must await more efficient methods to generate $t s h^{-}$and $e y^{-}$clones.

The proliferation-inducing ability of Ey, Tsh, and Hth is interesting in light of the fact that the mammalian homologs of $h t h$, the meis genes, are proto-oncogenes (Moskow et al. 1995; Allen et al. 2000). As discussed above, the proliferation we observe in Drosophila may require $w g$ signaling and the coexpression of $t s h$, which has been implicated in modulating wg signaling during Drosophila development (Erkner et al. 1999; Gallet et al. 
1999; Waltzer et al. 2001). Given these findings, it will be of interest to determine if the oncogenic potential of the meis genes also depends on the activities of $w g$ and/or tsh homologs.

\section{Combinatorial control of development by transcription factors}

Transcription factors often act in unique combinations to elicit distinct biological outputs. The combination examined here is Ey-Hth-Tsh. Because Hth and Tsh are also required for leg and wing development, Ey must make this combination specific for eye development. As discussed above, we suggest that this combination of factors is used transiently during eye development to promote the proliferation of eye disc cells and to prevent the premature expression of later-acting transcription factors that are required for eye development. Consistent with this second role, ectopic expression of Hth blocks eye development (Pai et al. 1998). Similarly, forcing the expression of Ey can also interfere with eye development (Curtiss and Mlodzik 2000; data not shown). The ability of these factors to repress eye development may in part be due to the ability of the Ey-Hth-Tsh combination to repress eya and dac.

In addition to the functions suggested here, Ey is also important for promoting eye morphogenesis and has been called the master regulator of eye development (Gehring 1996). In fact, Ey is likely to be a direct activator of so (Niimi et al. 1999; Punzo et al. 2002). We speculate that the eye-activating functions of Ey may be carried out in cells that express a different combination of transcription factors from those present in domain II. Cells in the PPN domain, for example, express Ey and Tsh, but not Hth. These cells also express so (Fig. 1). It is therefore possible that Ey activates $s o$ in the PPN domain (Fig. 9). In contrast, Ey-Hth-Tsh appears to repress eya, dac, and, by inference, so. As all three of these factors are DNA-binding proteins, one possibility is that they are part of a specific DNA-binding complex that directly regulates these, as well as other, target genes in domain II. A different set of target genes may be regulated by Ey (+/-Tsh) in the absence of Hth. A second possibility is that the regulation we observe here is indirect. Finally, our results are also consistent with a model in which Hth binds to Ey and blocks its ability to bind DNA. Such a mechanism has been proposed to account for repression of eye development by the Hox protein Antennapedia (Antp; Plaza et al. 2001). Toy, a second Pax6 family member in flies (Czerny et al. 1999), may also be part of the combinatorial control of eye development described here. An assessment of Toy's role is not possible at present, but will be important to characterize in the future.

The progression of the MF across the eye is an elegant mechanism for gradually changing the combination of transcription factors as development proceeds (Fig. 9). As with Hth, Ey, and Tsh; So, Eya, and Dac also have the ability to positively activate each other's expression (Bonini et al. 1997; Chen et al. 1997; Pignoni et al. 1997;
Shen and Mardon 1997). Thus, both ahead of and behind the $\mathrm{MF}$, eye disc cells are in different, but relatively stable states, in part because the factors expressed within these regions-Hth, Tsh, and Ey in domain II and Eya, So, and Dac posterior to the MF-can reinforce each other's expression. These two states are important for promoting proliferation and differentiation, respectively. Signals coming from the MF convert one state into another, and a key to flipping this switch is the repression of $h t h$ (Fig. 9). Remarkably, in the vertebrate retina Sonic hedgehog, a homolog of Drosophila Hh, is expressed in a wave-like fashion as retina cells differentiate (Neumann and Nuesslein-Volhard 2000). Furthermore, Pax6, the vertebrate ey homolog, is required to keep retinal cells multipotent (Marquardt et al. 2001), which is reminiscent of the uncommitted state of anterior cells in the fly eye disc. Given these intriguing parallels, it will be very interesting to determine if homologs of $h t h$ and $t s h$ play analogous roles in the vertebrate retina before the initiation of differentiation.

\section{Materials and methods}

\section{Genotypes and genetic manipulations}

Ectopic expression clones were generated randomly in eye discs by heat-shocking larvae, at $36^{\circ} \mathrm{C}$ for 30 min between 48 and 72 $\mathrm{h}$ after egg laying (second instar), from the following crosses: $y w$, hs-Flp; tub $>$ GFP, $y^{+}>$G4 (Zecca and Struhl 2002) or y, hs-Flp, actin > hsCD2 > Gal4 (Struhl and Basler 1993) females to UASGFP-hth, UAS-Tsh [from S. Kerridge (Centre Universitaire Marseille, Marseille, France)], or UAS-Ey (Halder et al. 1995) males. In some experiments, a hairy-lacZ reporter gene $\left(h^{08247}\right)$ was introduced in the genotype. To generate clones misexpressing more than one product, females from the stocks $\mathrm{yw}$, hs-Flp; $U A S-t s h ; t u b>G F P, y^{+}>G 4$ or yw, hs-flp; UAS-hth 4.0; tub $>$ GFP,$y^{+}>G 4$ were crossed to males harboring the other UAS transgene. Mutant clones were detected by the absence of GFP or by detection of the misexpressed protein.

For the generation of activated Tkv-expressing clones $\left(\mathrm{Tkv}^{\star}\right)$, larvae of the genotype y hs-Flp, act > hsCD2 > G4; UAS-TkV ${ }^{\mathrm{QD}}$ (Nellen et al. 1996) were heat-shocked as above. Clones were detected by the absence of CD2. To induce CD2 expression, larvae were heat-shocked at $37^{\circ} \mathrm{C}$ for $45 \mathrm{~min}$, followed by a recovery period at RT for $45 \mathrm{~min}$ prior to dissection.

The $h t h^{P 2}$ allele was used in loss-of-function experiments (Casares and Mann 2001; Kurant et al. 2001). $h t h^{P 2}$ clones were generated in ey-FLP1; FRT82B $h t h^{P 2} / F R T 82 B$ Ubi-GFP larvae. Because ey-FLP1 provides flipase in the eye-antennal disc, FRT clones are generated randomly in the eye disc throughout larval life (Newsome et al. 2000). ey $a^{-}$clones were induced in larvae of the genotypes ey-FLP1; ey $a^{1}$ or eya ${ }^{E 8}$ FRT4OA/armZ FRT4OA (Bonini et al. 1993; Hazelett et al. 1998) and marked by the absence of $\beta$-galactosidase ( $\beta$-gal). In some experiments, a $d p p-$ lacZ reporter (Blackman et al. 1991) was included in the genotype. dac clones were induced in larvae of the genotype eyFLP1; dac ${ }^{3}$ FRT40A/armZ FRT4OA (Mardon et al. 1994). mad clones were induced using the $\mathrm{mad}^{B 1}$ allele and FRT40A (FlyBase).

Wing disc misexpression of Ey was achieved with the Gal4/ UAS system (Brand and Perrimon 1993), using the MS1096, $v g B E-G a 14$, or $d p p^{b l k}$-Gal4 driver lines or the tub>GFP, $y^{+}>$Gal4 flip-out driver line (Capdevila et al. 1994; StaehlingHampton et al. 1994; Simmonds et al. 1998). 


\section{Immunostainings}

The antibodies used were: rabbit anti- $\beta$-gal (Cappell), mouse anti-rat CD2 (Serotec); guinea pig anti-Hth (Casares and Mann 1998), rat anti-Tsh (Wu and Cohen 2000), rabbit anti-Ey [gift from Patrick Callaerts (University of Houston, Houston, TX)], mouse anti-Dac (Mardon et al. 1994), mouse anti-Eya (Bonini et al. 1993), and rat anti-Elav 7E8A10 (O'Neill et al. 1994). For the quadruple staining shown in Figure $1 \mathrm{G}, d p p-1 a c Z$ larvae were stained for $\beta$-gal, Hth, Tsh, and Ey. $\beta$-gal and Hth were detected with the same secondary antibody. After image acquisition, their expression domains were represented in different colors. Secondary antibodies (FITC, Texas Red, and Cy5 conjugated) were from Jackson Laboratories. Imaginal discs were analyzed with Bio-Rad MRC600 or MRC1024 confocal systems.

\section{Protein interaction experiments}

His-tagged Exd and Hth constructs and the His-tagged Exd/untagged Hth constructs for making heterodimers were previously described (Ryoo et al. 1999). CG9403, a zinc-finger encoding gene, was cloned into the $\mathrm{pET} 14 \mathrm{~b}$ vector and used as a negative control. All constructs were transformed into BL21 bacteria and induced for $2 \mathrm{~h}$ with IPTG; bacterial extracts were prepared by disruption in lysis buffer $(50 \mathrm{mM}$ Tris at $\mathrm{pH} 7.5,100 \mathrm{mM} \mathrm{NaCl}$, $10 \mathrm{mM}$ imidizole, $0.08 \%$ sodium deoxycholate, and $0.1 \mathrm{mM}$ PMSF). Full-length Tsh [a gift from S. Kerridge (Centre Universitaire Marseille, Marseille, France)] and Ey [a gift from W. Gehring (Biozentrum-Universitat Basel, Basel, Switzerland)] pBluescript cDNA clones were used to generate ${ }^{35} \mathrm{~S}$-labeled proteins using rabbit reticulocyte lysates (TNT, Promega). Then 10 $\mu \mathrm{L}$ of labeled protein was incubated with $100 \mu \mathrm{L}$ of the bacterial lysate at $4^{\circ} \mathrm{C}$ for $2 \mathrm{~h} ; 20 \mu \mathrm{L}$ of prewashed $\mathrm{Ni}^{2+}$ beads were added for $1 \mathrm{~h}$; complexes were centrifuged and washed four times with RIPA buffer $(50 \mathrm{mM}$ Tris at $\mathrm{pH} 7.5,150 \mathrm{mM} \mathrm{NaCl}, 20 \mathrm{mM}$ $\mathrm{MgCl}_{2}, 0.5 \%$ NP-40, $0.5 \mathrm{mM}$ PMSF, and $10 \mathrm{mM}$ imidizole for Tsh or $30 \mathrm{mM}$ imidizole for Ey). Samples were resuspended in SDS loading buffer, separated using SDS-PAGE, and exposed to film.

Immunoprecipitations (IPs) were performed using $200 \mathrm{mg}$ of dechorionated 0-12-h OregonR embryos homogenized in RIPA buffer (50 mM Tris at $\mathrm{pH} 7.5,150 \mathrm{mM} \mathrm{NaCl}, 20 \mathrm{mM} \mathrm{MgCl}$, $0.5 \%$ NP-40, $0.5 \mathrm{mM}$ PMSF). An anti-Hth guinea pig polyclonal antibody (1:500) or preimmune serum (1:500) was added to the embryo lysates and incubated at $4^{\circ} \mathrm{C}$ overnight. Protein A/Gconjugated beads were added for $2 \mathrm{~h}$, centrifuged, and washed three times with RIPA buffer. SDS-PAGE and Western blot analyses were performed using a guinea pig polyclonal anti-Tsh antibody and an ECL detection kit (Amersham-Pharmacia).

\section{Acknowledgments}

We thank P. Callaerts, S.K. Chan, S. Cohen, W. Gehring, G. Mardon, M. Mlodzik, G. Struhl, J. Treisman, U. Walldorf, M. Zecca, L. Zipursky, and the Bloomington Stock Center for reagents. We thank Katy Stevens for the images of second-instar imaginal discs. We also thank M. Dominguez, T. Jessell, L. Johnston, and A. Tomlinson for advice and for comments on the manuscript. This work was supported by a grant from the N.I.H. to R.S.M., who is a Scholar of the Leukemia and Lymphoma Society. F.C. is an EMBO Young Investigator and Leukemia and Lymphoma Society Special Fellow and is also funded by Fundação para a Ciência e a Tecnologia de Portugal. J.B. was funded through an EMBO Young Investigator Award to F.C., and B.G. was supported by an individual NRSF award and an institutional NIH training grant.
The publication costs of this article were defrayed in part by payment of page charges. This article must therefore be hereby marked "advertisement" in accordance with 18 USC section 1734 solely to indicate this fact.

\section{References}

Abu-Shaar, M. and Mann, R.S. 1998. Generation of multiple antagonistic domains along the proximodistal axis during Drosophila leg development. Development 125: 3821-3830.

Allen, T.D., Zhu, Y.X., Hawley, T.S., and Hawley, R.G. 2000. TALE homeoproteins as HOX11-interacting partners in Tcell leukemia. Leuk. Lymphoma 39: 241-256.

Azpiazu, N. and Morata, G. 2000. Function and regulation of homothorax in the wing imaginal disc of Drosophila. Development 127: 2685-2693.

Baker, N.E. 1988. Transcription of the segment-polarity gene wingless in the imaginal discs of Drosophila, and the phenotype of a pupal-lethal wg mutation. Development 102: 489-497.

- 2001. Cell proliferation, survival, and death in the Drosophila eye. Semin. Cell Dev. Biol. 12: 499-507.

Baker, N.E. and Yu, S.Y. 2001. The EGF receptor defines domains of cell cycle progression and survival to regulate cell number in the developing Drosophila eye. Cell 104: 699708.

Baker, N.E., Yu, S., and Han, D. 1996. Evolution of proneural atonal expression during distinct regulatory phases in the developing Drosophila eye. Curr. Biol. 6: 1290-1301.

Baonza, A. and Freeman, M. 2001. Notch signalling and the initiation of neural development in the Drosophila eye. Development 128: 3889-3898.

Blackman, R.K., Sanicola, M., Raftery, L.A., Gillevet, T., and Gelbart, W.M. 1991. An extensive 3' cis-regulatory region directs the imaginal disk expression of decapentaplegic, a member of the TGF- $\beta$ family in Drosophila. Development 111: 657-666.

Bonini, N.M., Leiserson, W.M., and Benzer, S. 1993. The eyes absent gene: Genetic control of cell survival and differentiation in the developing Drosophila eye. Cell 72: 379-395.

Bonini, N.M., Bui, Q.T., Gray-Board, G.L., and Warrick, J.M. 1997. The Drosophila eyes absent gene directs ectopic eye formation in a pathway conserved between flies and vertebrates. Development 124: 4819-4826.

Brand, A. and Perrimon, N. 1993. Targeted gene expression as a means of altering cell fates and generating dominant phenotypes. Development 118: 401-415.

Brown, N.L., Sattler, C.A., Paddock, S.W., and Carroll. S.B. 1995. Hairy and emc negatively regulate morphogenetic furrow progression in the Drosophila eye. Cell 80: 879-887.

Bryant, P.J. 1978. Pattern formation in imaginal discs. In The genetics and biology of Drosophila (eds. M. Ashburner and T.R.F. Wright). pp. 229-335. Academic Press, London.

Burke, R. and Basler. K. 1996. Hedgehog-dependent patterning in the Drosophila eye can occur in the absence of Dpp signaling. Dev. Biol. 179: 360-368.

Capdevila, J., Estrada, M.P., Sanchez-Herrero, E., and Guerrero, I. 1994. The Drosophila segment polarity gene patched interacts with decapentaplegic in wing development. EMBO J. 13: 71-82.

Casares, F. and Mann, R.S. 1998. Control of antennal versus leg development in Drosophila. Nature 392: 723-726.

. 2000. A dual role for homothorax in inhibiting wing blade development and specifying proximal wing identities in Drosophila. Development 127: 1499-1508. 
. 2001. The ground state of the ventral appendage of Drosophila. Science 293: 1477-1480.

Chanut, F. and Heberlein, U. 1997. Role of decapentaplegic in initiation and progression of the morphogenetic furrow in the developing Drosophila retina. Development 124: 559567.

Chen, R., Amoui, M., Zhang, Z., and Mardon, G. 1997. Dachshund and eyes absent proteins form a complex and function synergistically to induce ectopic eye development in Drosophila. Cell 91: 893-903.

Cheyette, B.N., Green, P.J., Martin, K., Garren, H., Hartenstein, V., and Zipursky, S.L. 1994. The Drosophila sine oculis locus encodes a homeodomain-containing protein required for the development of the entire visual system. Neuron 12: $977-$ 996.

Curtiss, J. and Mlodzik, M. 2000. Morphogenetic furrow initiation and progression during eye development in Drosophila: The roles of decapentaplegic, hedgehog and eyes absent. Development 127: 1325-1336.

Czerny, T., Halder, G., Kloter, U., Souabni, A., Gehring, W.J., and Busslinger, M. 1999. twin of eyeless, a second Pax-6 gene of Drosophila, acts upstream of eyeless in the control of eye development. Mol. Cell 3: 297-307.

Desplan, C. 1997. Eye development: Governed by a dictator or a junta? Cell 91: 861-864.

Dominguez, M. 1999. Dual role for Hedgehog in the regulation of the proneural gene atonal during ommatidia development. Development 126: 2345-2353.

Erkner, A., Gallet, A., Angelats, C., Fasano, L., and Kerridge, S. 1999. The role of Teashirt in proximal leg development in Drosophila: Ectopic Teashirt expression reveals different cell behaviours in ventral and dorsal domains. Dev. Biol. 215: 221-232.

Fasano, L., Roder, L., Core, N., Alexandre, E., Vola, C., Jacq, B., and Kerridge, S. 1991. The gene teashirt is required for the development of Drosophila embryonic trunk segments and encodes a protein with widely spaced zinc finger motifs. Cell 64: 63-79.

Freeman, M. 1996. Reiterative use of the EGF receptor triggers differentiation of all cell types in the Drosophila eye. Cell 87: 651-660.

Friedrich, M. and Benzer, S. 2000. Divergent decapentaplegic expression patterns in compound eye development and the evolution of insect metamorphosis. I. Exp. Zool. 288: 39-55.

Gallet, A., Angelats, C., Erkner, A., Charroux, B., Fasano, L., and Kerridge, S. 1999. The C-terminal domain of armadillo binds to hypophosphorylated teashirt to modulate wingless signalling in Drosophila. EMBO J. 18: 2208-2217.

Gehring, W.J. 1996. The master control gene for morphogenesis and evolution of the eye. Genes Cells 1: 11-15.

Gonzalez-Crespo, S. and Morata, G. 1995. Control of Drosophila adult pattern by extradenticle. Development 121: 2117-2125.

Gonzalez-Crespo, S., Abu-Shaar, M., Torres, M., Martínez-A, C., Mann, R.S., and Morata, G. 1998. Antagonism between extradenticle function and Hedgehog signalling in the development limb. Nature 394: 196-200.

Greenwood, S. and Struhl, G. 1999. Progression of the morphogenetic furrow in the Drosophila eye: The roles of Hedgehog, Decapentaplegic and the Raf pathway. Development 126: 5795-5808.

Halder, G., Callaerts, P., and Gehring, W.J. 1995. Induction of ectopic eyes by targeted expression of the eyeless gene in Drosophila. Science 267: 1788-1792.

Hazelett, D.J., Bourouis, M., Walldorf, U., and Treisman, J.E. 1998. decapentaplegic and wingless are regulated by eyes absent and eyegone and interact to direct the pattern of retinal differentiation in the eye disc. Development 125: 37413751.

Horsfield, J., Penton, A., Secombe, J., Hoffman, F.M., and Richardson, H. 1998. decapentaplegic is required for arrest in $\mathrm{G}_{1}$ phase during Drosophila eye development. Development 125: 5069-5078.

Jarman, A.P., Grell, E.H., Ackerman, L., Jan, L.Y., and Jan, Y.N. 1994. Atonal is the proneural gene for Drosophila photoreceptors. Nature 369: 398-400.

Kronhamn, J., Frei, E., Daube, M., Jiao, R., Shi, Y., Noll, M., and Rasmuson-Lestander, A. 2002. Headless flies produced by mutations in the paralogous Pax6 genes eyeless and twin of eyeless. Development 129: 1015-1026.

Kurant, E., Eytan, D., and Salzberg, A. 2001. Mutational analysis of the Drosophila homothorax gene. Genetics 157: 689-698.

Lee, J.D. and Treisman, J.E. 2001. The role of Wingless signaling in establishing the anteroposterior and dorsoventral axes of the eye disc. Development 128: 1519-1529.

Ma, C. and Moses, K. 1995. Wingless and patched are negative regulators of the morphogenetic furrow and can affect tissue polarity in the developing Drosophila compound eye. Development 121: 2279-2289.

Mann, R.S. and Affolter, M. 1998. Hox proteins meet more partners. Curr. Opin. Genet. Dev. 8: 423-429.

Mardon, G., Solomon, N.M., and Rubin, G.M. 1994. dachshund encodes a nuclear protein required for normal eye and leg development in Drosophila. Development 120: 3473-3486.

Marquardt, T., Ashery-Padan, R., Andrejewski, N., Scardigli, R., Guillemot, F., and Gruss, P. 2001. Pax6 is required for the multipotent state of retinal progenitor cells. Cell 105: 43-55.

Moskow, J.J., Bullrich, F., Huebner, K., Daar, I.O., and Buchberg, A.M. 1995. Meis1, a PBX1-related homeobox gene involved in myeloid leukemia in BXH-2 mice. Mol. Cell. Biol. 15: 5434-5443.

Nellen, D., Burke, R., Struhl, G., and Basler, K. 1996. Direct and long-range action of a DPP morphogen gradient. Cell 85: 357-368

Neumann, C.J. and Nuesslein-Volhard, C. 2000. Patterning of the zebrafish retina by a wave of sonic hedgehog activity. Science 289: 2137-2139.

Newsome, T.P., Asling, B., and Dickson, B.J. 2000. Analysis of Drosophila photoreceptor axon guidance in eye-specific mosaics. Development 127: 851-860.

Niimi, T., Seimiya, M., Kloter, U., Flister, S., and Gehring, W.J. 1999. Direct regulatory interaction of the eyeless protein with an eye-specific enhancer in the sine oculis gene during eye induction in Drosophila. Development 126: 2253-2260.

O'Neill, E.M., Rebay, I., Tjian, R., and Rubin, G.M. 1994. The activities of two Ets-related transcription factors required for Drosophila eye development are modulated by the Ras/ MAPK pathway. Cell 78: 137-147.

Pai, C.-Y., Kuo, T., Jaw, T., Kurant, E., Chen, C., Bessarab, D., Salzberg, A., and Sun, Y. 1998. The Homothorax homeoprotein activates the nuclear localization of another homeoprotein, extradenticle, and suppresses eye development in Drosophila. Genes \& Dev. 12: 435-446.

Pan, D. and Rubin, G.M. 1998. Targeted expression of teashirt induces ectopic eyes in Drosophila. Proc. Natl. Acad. Sci. 95: 15508-15512.

Pichaud, F. and Casares, F. 2000. homothorax and iroquois- $C$ genes are required for the establishment of territories within the developing eye disc. Mech. Dev. 96: 15-25.

Pignoni, F. and Zipursky, S.L. 1997. Induction of Drosophila eye development by decapentaplegic. Development 124: 271278. 
Pignoni, F., Hu, B., Zavitz, K.H., Xiao, J., Garrity, P.A., and Zipursky, S.L. 1997. The eye-specification proteins So and Eya form a complex and regulate multiple steps in Drosophila eye development. Cell 91: 881-891.

Plaza, S., Prince F., Jaeger, J., Kloter, U., Flister, S., Benassayag, C., Cribbs, D., and Gehring, W.J. 2001. Molecular basis for the inhibition of Drosophila eye development by Antennapedia. EMBO J. 20: 802-811.

Punzo, C., Seimiya, M., Flister, S., Gehring, W.J., and Plaza, S. 2002. Differential interactions of eyeless and twin of eyeless with the sine oculis enhancer. Development 129: 625-634.

Ready, D.F., Hanson, T.E., and Benzer, S. 1976. Development of the Drosophila retina, a neurocrystalline lattice. Dev. Biol. 53: $217-240$.

Reifegerste, R. and Moses, K. 1999. Genetics of epithelial polarity and pattern in the Drosophila retina. Bioessays 21: 275285.

Rieckhof, G., Casares, F., Ryoo, H.D., Abu-Shaar, M., and Mann, R.S. 1997. Nuclear translocation of Extradenticle requires homothorax, which encodes an Extradenticle-related homeodomain protein. Cell 91: 171-183.

Ryoo, H.D., Marty, T., Casares, F., Affolter, M., and Mann, R.S. 1999. Regulation of Hox target genes by a DNA bound Homothorax/Hox/Extradenticle complex. Development 126: $5137-5148$

Sekelsky, J.J., Newfeld, S.J., Raftery, L.A., Chartoff, E.H., and Gelbart, W.M. 1995. Genetic characterization and cloning of mothers against dpp, a gene required for decapentaplegic function in Drosophila melanogaster. Genetics 139: 13471358.

Shen, W. and Mardon, G. 1997. Ectopic eye development in Drosophila induced by directed dachshund expression. Development 124: 45-52.

Simmonds, A.J., Liu, X., Soanes, K.H., Krause, H.M., Irvine, K.D., and Bell, J.B. 1998. Molecular interactions between Vestigial and Scalloped promote wing formation in Drosophila. Genes \& Dev. 12: 3815-3820.

Staehling-Hampton, K., Jackson, P.D., Clark, M.J., Brand, A.H., and Hoffmann, F.M. 1994. Specificity of bone morphogenetic protein-related factors: Cell fate and gene expression changes in Drosophila embryos induced by decapentaplegic but not 60A. Cell Growth Differ. 5: 585-593.

Struhl, G. and Basler, K. 1993. Organizing activity of wingless protein in Drosophila. Cell 72: 527-540.

Treisman, J.E. 1999. A conserved blueprint for the eye? Bioessays 21: 843-850.

Treisman, J.E. and Heberlein, U. 1998. Eye development in Drosophila: Formation of the eye field and control of differentiation. Curr. Top. Dev. Biol. 39: 119-158.

Treisman, J.E. and Rubin, G.M. 1995. wingless inhibits morphogenetic furrow movement in the Drosophila eye disc. Development 121: 3519-3527.

Waltzer, L., Vandel, L., and Bienz, M. 2001. Teashirt is required for transcriptional repression mediated by high Wingless levels. EMBO J. 20: 137-145.

Wiersdorff, V., Lecuit, T., Cohen, S.M., and Mlodzik, M. 1996. Mad acts downstream of Dpp receptors, revealing a differential requirement for dpp signaling in initiation and propagation of morphogenesis in the Drosophila eye. Development 122: $2153-2162$

Wolff, T. and Ready, D.F. 1991. The beginning of pattern formation in the Drosophila compound eye: The morphogenetic furrow and the second mitotic wave. Development 113: $841-850$.

Wu, J. and Cohen, S.M. 1999. Proximodistal axis formation in the Drosophila leg: Subdivision into proximal and distal do- mains by Homothorax and Distal-less. Development 126: $109-117$.

. 2000. Proximal distal axis formation in the Drosophila leg: Distinct functions of teashirt and homothorax in the proximal leg. Mech. Dev. 94: 47-56.

- 2002. Repression of Teashirt marks the initiation of wing development. Development 129: 2411-2418.

Zecca, M. and Struhl, G. 2002. Control of growth and patterning of the Drosophila wing imaginal disc by EGFR-mediated signaling. Development 129: 1369-1376. 


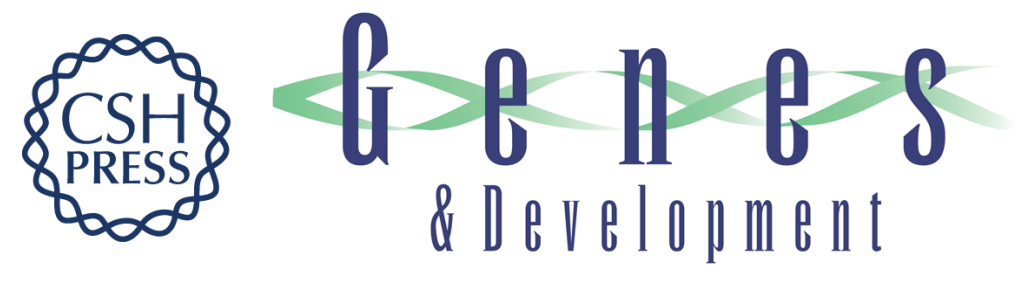

\section{Combinatorial control of Drosophila eye development by Eyeless, Homothorax, and Teashirt}

Jose Bessa, Brian Gebelein, Franck Pichaud, et al.

Genes Dev. 2002, 16:

Access the most recent version at doi:10.1101/gad.1009002

References

This article cites 77 articles, 44 of which can be accessed free at: http://genesdev.cshlp.org/content/16/18/2415.full.html\#ref-list-1

License

Email Alerting

Receive free email alerts when new articles cite this article - sign up in the box at the top Service right corner of the article or click here.

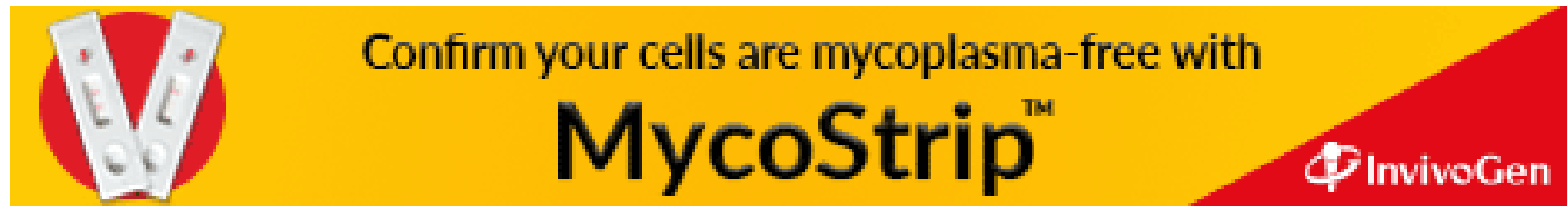

